\title{
A European Constitution and European constitutional legal practice
}

\author{
Aalt Willem Heringa
}

(C) China-EU School of Law 2013

Constitutions of countries and of major organisations such as the European Union (EU) are abstract documents yet they relate to fundamental issues and important sentiments among the population. The EU's failed project to implement a European Constitution illustrates such sensitivities. Recently, David Cameron, the Prime Minister of the United Kingdom (UK) delivered a speech in which he criticised fundamental aspects of the EU, such as the broad powers of the EU and the need for greater flexibility.

The main issues of contention relate to the mode and scope of constitutional governance in the EU. In particular, the opinion of the general population is that EU governance is far removed from the needs of the public. The economic crisis has increased the magnitude of such public sentiments especially after the EU was forced to intervene in order to save indebted countries and banks. These measures have not only led to criticism in the countries concerned but also within the rest of the EU. In the countries concerned, it was felt that the EU (and the European Central Bank and the International Monetary Fund) forced them to accept drastic rescue measures contrary to the concept and practice of state sovereignty. In other EU countries having more robust economies it was felt that they were called upon to rescue other states and banks that had irresponsibly spent money and undertook unwise fiscal policies. Essentially, this debate is a constitutional debate. The issue impinges upon the solidarity of the entities that make up the EU. Of major concern is how to make transparent, well designed policies that are put into practice. Adequate structures, mechanisms, supervision and legitimacy are paramount to successful democracy and constitutional governance.

\footnotetext{
A. W. Heringa $(\bowtie)$

China EU School of Law, Beijing, China

e-mail: aw.heringa@maastrichtuniversity.nl
}

A. W. Heringa

Department of (Comparative) Constitutional Law, Maastricht University,

Maastricht, The Netherlands 
In 2014, elections to the European Parliament will be held in all member states and there will also be the selection of a new Commission and Commission President. The most important concern for this upcoming election year is how to realise legitimate EU policy making and create appropriate mechanisms for effective, democratic and transparent decision making in the domains that go to the hearts of the Europeans so as to create a socially and economically sound European community.

The EU is not alone in enduring a phase of economic crisis and a crisis involving the legitimacy of nationwide decision-making. The US has had its own share of problems regarding political stalemate and issues related to the proper powers of the national legislature. The 2008 global economic crisis has also an effect upon constitutionalism and the constitutional functioning of states. Public awareness of the power of international financial markets, the weaknesses of such concepts as sovereignty, and the importance of solidarity and democratic legitimacy have also been heightened as a result of the global economic crisis.

Democracy is a difficult concept to implement in a large federation such as the US, with its 50 states. It is even more challenging in the EU, made up of 28 states, where people speak different languages, have strong views supporting sovereignty, varied cultures and different histories.

When the EU was initially established, it was organised as an economic and coal and steel community. Gradually the EU has evolved into what it is todayencompassing a European Monetary Union and exercising wide powers. However, at the same time it is clear that the EU lacks the power to deal with issues such as foreign affairs, defence, economic, fiscal and monetary policies, which are usually identified with a sovereign state. Many domestic politicians, whom are indeed nationally elected, still seem to believe that they can act as sovereigns, but then realise that the EU (co)determines and influences budgetary policies as well, by checking the national budgets. This leads to a multi-layered situation of two systems that exist side-by-side yet fight for prevalence and priority instead of harmonisation and collaboration.

The size of democracies and systems also raise a further bone of contention. Robert Dahl has written about this phenomenon and has noted that it is important that the public are not only able to grasp a constitutional model but they also need to be able to oversee it, understand it and to feel close to it.

Constitutionalists have for many years worked with a model based on the separation of powers. The doctrine of the separation of powers divides the state into three branches: legislative, executive and judicial. The aim of the separation of powers is to prevent power from being overly concentrated in one branch. Power is divided between the three branches and each branch carries out checks and balances on the other. The EU has constructed a different model of collaboration, which focuses less on separation. However, this model has not led to the reduction of conflict between states.

What is however notable is that constitutional discussions are visible and permanent. Topics for discussion include: further economic cooperation, a banking union, rescue mechanisms, fiscal policies in the member states, transparency and legitimacy, elections and the composition of the European Commission, and the 
(scope) of the competences of the EU and many other issues. It is a forum whereby lawyers and politicians; journalists and scholars can engage in heated arguments about the EU.

From the perspective of an outsider, it certainly appears that the EU is divided from these discussions. However, when one reflects upon the last half century, it is undeniably true that progress has been made. The question is whether the progress is sufficient to keep up with global competition. It is a positive feature of the EU and its countries as open societies that discussions can and do take place, and that all involved can engage. Conversely, discourse within the US seems to be far more polarised, with less incentive to compromise to reach a solution.

This China-EU Law Journal is about making comparative law and comparative research visible and practical. We may do so in many domains of the law and with special reference to China and the EU. All countries in the world are constantly engaged in debate about their constitutional model and role. Constitutions are amended and constitutional structures undergo change. Here we can learn from each other. It is not so long ago that countries within the continent, Europe, engaged in a public attempt to draft a constitution, which though the document was not as such adopted, later re-emerged in the Lisbon treaties. The general public are more educated than in the past; the (social) media play a role in public debate; people seek and find inspiration in experiences elsewhere and make democracy a topical concept.

I do hope that we can make many comparative law subjects part of the debate in this Journal, in the China EU School of Law, and as part of the China EU dialogue. And, that we may do so whilst being critical and open about our comparative tools, yardsticks and comparators. We may discuss legal transplants, rejections of foreign legal concepts and seek inspiration from comparative law. I conclude that we will ultimately benefit from the adventures of comparative law and the many lessons that we can learn. 